\title{
The Relationships among Service Quality, Trust, User Satisfaction and Post-adoption Intentions in M-payment Services
}

\author{
Nobukhosi Dlodlo \\ Lecturer: Department of Marketing and Sport Management \\ Faculty of Management Sciences, Vaal University of Technology \\ Private Bag X021, Vanderbijlpark, 1900 \\ Email: nobukhosid@vut.ac.za
}

\section{Doi:10.5901/mjss.2014.v5n23p165}

\section{Abstract}

The major interest of businesses is continued usage of services, which is sustainable in the long-term. Surprisingly, postadoption usage of technology has seldom received attention from researchers, particularly within the context of mobile payment services although this component is considered the most significant element as it translates into user' retention rates, culminating into loyalty towards the service provider. This study addressed the knowledge gap in the area of M-payment postadoption in general and also in South Africa, specifically. The purpose of this study therefore, was to fill this void by examining the influence of service quality on continuance intentions and the mediating role of M-payment trust and user satisfaction. The study followed a quantitative survey approach in which data were collected from a sample of 269 experienced M-payment users based in South Africa. Five hypotheses were posited and a model was tested using Structural Equation Modelling software LISREL to ascertain the model fit. The study provides strong support for positive and significant relationships between service quality with trust $(p<.01)$ while the existence of statistically significant relationships' were also noted between the latter with user satisfaction $(p<.05)$. However, the study could not corroborate the significance of the service quality and satisfaction path. In addition, both trust $(p<.10)$ and satisfaction $(p<.01)$ demonstrated positive and significant influence on the users' decision to continue using M-payment services. As such, service providers can improve service quality and trust components with a view to improve the experiences of M-payment users, further promoting continuance usage.

Keywords: M-payment, continuance intention, trust, satisfaction, service quality

\section{Introduction}

Cawley and Hynes (2010) contend that near universal access to the mobile phone as a technological device has been achieved. In addition, a report from the International Telecommunications Union (ITU, 2011) opined that; Western Europe exhibits the highest penetration of mobile phones and wireless-enabled devices (79\%), followed by North America (48\%); Asia (14\%); Latin America (12\%) and Africa (10\%), respectively. This status quo has morphed mobile devices into an ultimate commercial transactions platform; that enables business entities to establish a universal electronic presence (Zhou, 2013). Similarly, the last decade has seen extensive alterations in the payment systems used in business activities, driven by the insurgence of recent technologies such as the Internet and social networks. Notwithstanding the kinesis of today's modern society, a sharp surge in the need for quick, safe and convenient money banking systems has been observed (Kim, Mirusmonov \& Lee, 2010). Mobile payment services have been suggested as a solution to facilitate micropayments in electronic commerce (e-commerce) environments with a view to provide an alternative for the diminishing use of hard cash.

Mobile payment (thereafter referred to as M-payment) refers to a mobile financial business transactions that are operated through a technological device that functions through a mobile network. Different researchers and institutions have defined this concept from different perspectives. For example, Au and Kauffman (2008:152) defined M-payment as "any payment in which a mobile device is utilised to initiate, authorize and confirm a commercial transaction". The phase of M-payment development is currently in transition with numerous markets presenting a history of tried and failed solutions and a future of promising but yet uncertain possibilities with potential new technology innovations. However, the most visible impact of the convergence between mobile and banking technology outside South Africa is the success of the M-Pesa money transfer service in Kenya, which has been replicated with limited success so far in South Africa by Nedbank (Grubb, 2012). M-Pesa has contributed towards the extensive growth of the Kenyan economy, making it one of the top three contributors to the East African countries' annual gross domestic product. In addition, Kenya takes first 
place in the African rankings on the M-payments Readiness Index (MPRI=44.4), followed closely by Nigeria (MPRI=31.3) and Egypt (MPRI=30.2), respectively (Mastercard, 2012).

The author's interest in the research of mobile payments is motivated by a number of reasons. Academically, the subject of mobile payments is an interesting, yet challenging field of study due to its infancy. It received only wider interest in the middle of the 2000s with an increasing number of peer-reviewed papers being published (Dahlberg, Mallat, Ondrus and Zmijewska, 2008). However, most of these studies focused on user adoption factors and market analyses. Little attention has been given to issues of theoretical models in the context of mobile payment (Pousttchi, Schiessler \& Wiedemann, 2008) indicating that there is need for a replication of studies exploring a plethora of factors that could potentially enhance the continuous usage of M-payment services.

\subsection{Continuance intention}

Behavioural intention can be defined as the degree to which a person has formulated conscious plans to perform or not to perform some specified future behaviour (Fishbein \& Aizen, 1975:97). As such, continuance intentions are a type of behavioural intention that is correlated with the behaviour itself (Zhou, 2013). Therefore, continuance intention is a measure of one's possible action or intention; which can be used to predict the likelihood of an individual deciding to continue (or not) utilising M-payment services.

\subsection{Service quality}

Parasuraman, Zeithaml and Malhotra (2005:5) defined service quality as 'all phases of a customer's interactions with a service provider while Zeithaml, Berry and Parasuraman (1996) conceptualised service quality as the overall impression of customers towards the service weakness or supremacy. Ducker (1991) defined service quality as what the customer gets out and is willing to pay for rather than what the supplier puts in. Therefore service quality frequently has been conceptualized as the difference between the expected performance and the actual performance (Zhao, Lu, Zhang \& Chau, 2012). Following on from these schools of thought, the concept of service quality in M-payment contexts may be captured as the consumers' overall evaluation and judgment of the delivery of service in a mobile, virtual business arena.

\subsection{Trust}

Van Der Heijden, Verhagen and Creemers (2003; in Lassala, Ruiz, \& Sanz, 2010) defined trust in online purchasing as the willingness of one of the parties (the payer) to be vulnerable to the actions of a virtual establishment, based on the expectation that this virtual establishment will carry out an important action for the customer, regardless of his or her ability to conduct or control the virtual establishment. As such, received wisdom has labelled this construct as knowledgebased trust as it incorporates the cognitive assertion by an individual in the trustworthiness of others as determined by their perceived competence, benevolence and integrity (McKnight, Choudhury, \& Kacmar, 2002). Therefore, in line with Lin (2011) when monetary transactions are conducted on the mobile platform, the customer is concerned about whether or not the service provider has adequate knowledge and skills (competence) to deliver on promises (integrity) while taking the customers' interests to consideration (benevolence). On the other hand, behavioural trust is based on the user's willingness or desire to follow a particular pattern of behaviour based on the expectation that the trustee will perform a particular action that is important for the trustor, regardless of the capacity of the trustor to survey or control the trustee (Mayer, Davis \& Schoorman, 1995). Built on mobile networks and terminals, mobile payment involves great risk since the networks may be susceptible to hacker attack, information interception, infection by viruses and Trojan horses. As such, it remains imperative for the web vendors to build trust in order to mitigate these perceived risks and facilitate the continuance usage of mobile payments (Siau \& Shen, 2003). Trust has been identified to be a significant factor facilitating user behaviour (Gefen, 2002). This study will conceptualise trust in M-payment from two perspectives; (1) trust in mobile technology and (2) trust in the mobile vendors.

\subsection{Satisfaction}

In the field of mobile services, literature is awash with a preponderance of debates as to whether satisfaction is an attitude or a relatively transient consumption-specific construct, or whether it is an outcome or an evaluative construct. From a cognitive perspective, satisfaction has been defined using the expectations disconfirmation paradigm (Oliver 1980:462). This paradigm suggests that a customer's feelings of satisfaction result from a mental comparison of the 
expectations presented at the beginning of the transaction encounter and the actual performance received. If the service performance exceeds the customer's expectations, then the customer is very satisfied (or delighted) and positively disconfirming (Hallowell, 1996:29). However, if the service performance falls short of customer expectations, this is referred to as dissatisfaction or negative disconfirming. On the contrary, the second line of research suggests that satisfaction is an affective, rather than cognitive, construct (Oliver, 1980; Cronin, Brady \& Hult, 2000). Rust and Oliver (1994:15) asserted that both approaches are indispensable at aiming to acquire a good definition of the construct. They defined satisfaction as the 'customer's fulfilment response' which is both an evaluation as well as an emotion-based response. Thus, satisfaction provides an indication of the customer's beliefs about the probability of a service leading to a positive feeling. This study satisfaction will incorporate the post-payment evaluation (transaction-specific) and emotional recognition of the entire M-payment service and interaction with the service provider (cumulative).

\section{Underlying Theory and Hypothesis Development}

The information systems (IS) model that was proposed by DeLone and McLean (1992) will be used as the theoretical base to inform the development of a more comprehensive M-payment success construct. The IS model argues that system quality and information quality affect use and user satisfaction, both of which further lead to individual impact and organisational impact. Later, this model was updated to include service quality (DeLone \& McLean, 2004) while Kim et al. (2010) compared the effects of system quality, information quality and service quality on initial trust and repeat trust building. Zhou (2013) highlighted that it is necessary to generalize the variables used in the IS success model by identifying the factors affecting M-payment continuance usage. However, as it is relatively difficult to measure actual continuance usage, the study will test continuance intention as a substitute.

Earlier studies found direct relationship between service quality and satisfaction (Cronin and Taylor, 1992; Cronin \& Taylor, 1994; Cronin et al., 2000; Shin \& Kim, 2008; Parasuraman, Zeithaml \& Berry, 1988). Cronin et al. (2000) stated that favourable service quality perceptions improve satisfaction. Satisfaction literature also relates switching intentions to service quality. Studies of Yeh and Li (2009) showed that service quality has direct effect on behavioural intentions through satisfaction. While perceived service quality is high, satisfaction will also be high and then switching tendency of the customers will be low. If M-payment is neither stable nor reachable when paying bills by mobile phones, users may be dissatisfied (Meharia, 2012). In addition, service quality has been identified as a predictor of user satisfaction with mobile instant messaging (Deng, Lu Wei \& Zhang, 2010) as well as satisfaction with mobile-value added services (Kim et al., 2010). Therefore, the aforementioned empirical evidence provides support for the postulation of the following hypothesis for the study:

\section{$\mathrm{H}_{1}$ : Service quality of M-payment is positively associated with satisfaction}

The importance of trust is highlighted in electronic and mobile commerce because of the spatial and temporal separation between the buyer and seller when buyers are required to give delicate personal information such as telephone numbers or credit card number to the merchant (Lee \& Chung, 2009). Trust provides a subjective guarantee that users will obtain a good experience in future as it is based on the belief that mobile payment service providers possess the ability, integrity and benevolence to present quality services (Zhou, 2013). In contrast, if service providers present unreliable services and slow responses to users, the attributes related to trust cannot be fostered. Extant research has disclosed the effect of service quality on user trust among online vendors (Gefen, 2002) as well as mobile banking service providers (Lee \& Chung, 2009). Therefore it is expected that high quality M-payment services will serve to foster feelings of trust among users. It is against this background that the following hypothesis is proposed for the study:

\section{$\mathrm{H}_{2}$ : Service quality of M-payment is positively associated with trust}

Previous studies have found trust as a significant determinant influencing customers' satisfaction along electronic commerce platforms (Gefen, Straub \& Boudreau, 2000; Jarvenpaa, Lang, Takeda \& Tuunainen, 2003). Consumers' concerns about the privacy and security of mobile payments are commonly related to authentication and confidentiality issues as well as to concerns about secondary use and unauthorized access to payments and user data. Perceived security and trust are thus expected to have an influence on the users' overall satisfactory evaluation of the M-payment service. Therefore, it is against this background that the following hypothesis is formulated for the study:

\section{$\mathrm{H}_{3}$ : Trust of M-payment services is positively associated with satisfaction}

User Satisfaction is considered as an important element for building loyalty and continuance usage of M-payment service (Sanayei, Ranjbarian, Shaemi \& Ansari, 2011). In the context of M-payment, user satisfaction includes three main facets: (1) satisfaction with processes and systems used for transactions, (2) satisfaction with the products and services from the service provider and (3) satisfaction with the information provided and updated through the mobile device 
platform (Wang \& Liao 2007). Similarly, in line with the Information Systems (IS) continuance model that was postulated by Bhattacherjee (2001), satisfaction has a direct impact on users' continuance intention of IS usage. Extant research has found that satisfaction is a strong determinant of continuance behaviour (Zhou, 2013; Kuo, Wu \& Deng, 2009). The theoretical path has been found to be significant in a number of e-commerce studies (Luo, Zhang \& Shim, 2010; Yen \& Li, 2009; Lin, Wu, \& Tsai 2005). In addition, satisfaction has been found to be positively related to future M-payment usage (Zhou, 2013). If the consumers are not satisfied with the interactions they engage in along mobile platforms, they may discontinue their usage (Lin \& Wang, 2006). Therefore, the foregoing evidence provides support for the postulation of the following hypothesis:

\section{$\mathrm{H}_{4}$ : Satisfaction of M-payment services is positively associated with continuance intentions}

In online service literature, the concept of trust is based on the idea of a relationship between a user and a service provider, which is often seen as a substitute for human contact between the company and its consumers. Built on mobile networks and terminals, mobile payment involves great uncertainty and risk since the networks may be susceptible to hacker attack, information interception, infection by viruses and Trojan horses. As such, it remains imperative for the web vendors to build trust in order to mitigate these perceived risks and facilitate the continued use of mobile payments. Trust generally drives purchases, online disclosures as well as deeper, more loyal relationships, which are a primary goal for a majority of e-commerce service providers (Gefen, 2002). Previous scholars have posited that trust plays a pivotal role in predicting the success rate of mobile technology services (Chandra, Srivastava \& Theng, 2010; Chen \& Barnes, 2007; Misra \& Wickamasinghe, 2004). Trust has also been identified to be a significant factor facilitating increased e-commerce transactions (Luo et al., 2010). Therefore, as a reflection on the increasing importance of trust in mobile technology use, trust is proposed in this study as an antecedent variable to continued M-payment usage. Therefore, it is against this background that the following hypothesis has been formulated for this study:

\section{$\mathrm{H}_{5:}$ Trust with M-payment services is positively associated with continuance intentions}

Based on a synthesis of the converging literature related to the research constructs, a framework is proposed to guide the empirical study as shown in Figure 1. The framework suggests that service quality (SQ) is the predictor variable, while user satisfaction (SAT) and M-payment trust (TRU) are the mediating variables for the study. Similarly, continuance intention $(\mathrm{Cl})$ is presented as the endogenous variable. The proposed conceptual linkages among these constructs is as follows: service quality provides the starting point for the model and directly affects the level with which users will either be satisfied with $\left(\mathrm{H}_{1}\right)$ or even trust $\left(\mathrm{H}_{2}\right)$, the M-payment service options. In turn, as security systems on the M-payment platforms increase, the users are expected to gain more confidence, leading to trust of the M-payment services of which the element of trust will serve to enhance the level of satisfaction among users $\left(\mathrm{H}_{3}\right)$. Finally, both satisfaction and trust are expected to influence M-payment continuance intentions ( $\mathrm{H}_{4}$ and $\mathrm{H}_{5}$ respectively). The constructs presented in this study will assist to broaden the body of scholarly conversations surrounding M-payment by providing relatable experiences of the South African users.

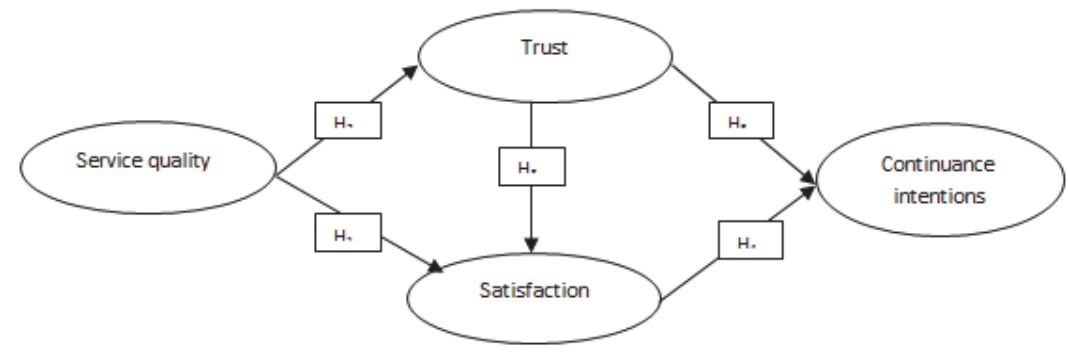

Figure 1: Conceptual framework

\section{Purpose of the Study}

The main objective of this study was to examine the post-adoption of mobile payment services in South Africa. A theoretically grounded model that incorporates service quality, trust and satisfaction was tested. However, since it is relatively difficult to measure actual continuance usage, this study will examine continuance intention (dependent variable) as a substitute. 


\section{Research Methodology}

\subsection{Measures and instrumentation}

To measure the constructs in the research model, multi-item scales that were previously validated by other researchers were adapted in the study. All items were modified to fit the mobile payment services context. Eight measurement scales of service quality were adapted from Brady and Cronin (2001), Lu, Zhang and Wang (2010) as well as Kim et al. (2010) with items relating to the access speed, ease-of-use, information relevance, sufficiency, reliability, responsiveness, assurance and personalisation. To measure user satisfaction, three items primarily adapted from service marketing literature were employed to measure transaction-specific satisfaction (Olsen \& Johnson, 2003; Bhattacherjee, 2001; Smith, Bolton \& Wagner, 1999) and an additional four items from mobile services research were adapted to measure cumulative satisfaction, contentment and pleasure derived while using mobile payment (Oliver, 1993; Smith et al., 1999). The perceived trust six-item scale was adapted from Pavlou (2003), Chiou and Droge (2006) as well as Lee and Chung (2009) Items of trust measure service providers' ability, integrity and benevolence, honesty, motives and accuracy. Lastly, the four items measuring continuance intention were taken from prior studies on re-purchase intention in mobile services contexts (Zhou, 2013; Kim, Choi \& Han, 2009). Thus, a total of twenty five items were used to measure the constructs. For each item, a seven-point Likert scale was used with anchors from "1=strongly disagree" to "7=strongly agree". Moreover, a section on the demographic profile of the respondents was included in the questionnaire with variables relating to the gender, age, education, marital status, frequency of M-payment use as well as the preferred M-payment service option. These questions were structured on dichotomous, multiple choice and ranking-order closed-ended scales, respectively.

In order to validate the sub-scales, firstly qualitative personal interviews (de-briefing exercise) were conducted so as to guarantee the validity of the terms used. The response from the three Marketing professors who were consulted led to some changes on the questionnaire, consistent with the specific characteristics of the industry surveyed and the research setting, thus qualifying the prima facie validity of the constructs. The use of experts as judges of a scale's domain is common in marketing (e.g., Babin \& Burns, 1998; Sweeney \& Soutar, 2001). After a number of amendments to item wording, question order and layout, the modified survey instrument was then pre-tested on a conveniently selected sample of 30 respondents after which, there were no substantive concerns and the questionnaire was deemed suitable for final data collection.

\subsection{Sample and data collection}

A non-probability convenience sampling method was used in the study to randomly select qualifying respondents. A sample size of 300 online shoppers was chosen for the study. The target population comprised both male and female respondents of various age groups (18 years and older) who are actively involved in conducting payments on their mobile devices because it is believed that they can offer valuable contributions to the study (Churchill \& lacobucci, 2002). Primary data was collected from the respondents using a self-administered, multi-dimensional survey questionnaire. The survey was conducted over the course of 16 weeks between February and May, 2014 through visiting universities, companies, research institutes, public spaces and Internet cafes using self-administered questionnaires as well as e-mail surveys. To ensure that the measured beliefs were based on direct behavioural experience with the object and thereby facilitate external validity of the study, the respondents were asked if they had previous minimum experience with mobile payment usage ( $\geq 6$ months). In addition, respondents younger than 18 and non-users of mobile commerce facilities were considered non-eligible and therefore, excluded from the study. However, those who consented to having minimum experience with M-payment systems were invited to fill the questionnaire based on their usage experience.

The researcher was involved in the fieldwork and played an active role in explaining the purpose of the study to the respondents. The cover letter explained the legitimacy of the study, provided assurance that responses would remain confidential and thanked the prospective participant for their assistance. The respondents were given adequate time to complete the questionnaire (approximately 20 minutes) and were assured of the participants' right to anonymity informed consent. In addition, participants were advised that they were free to withdraw from the study at any-time. Furthermore, confectionary was provided to each participant as an incentive with a view to improve response rates. Out of the 300 questionnaires that were distributed, 282 were returned and scrutinised, 13 responses were dropped owing to too many missing values. As a result, 269 questionnaires were retained as valid responses for the study, giving a response rate of 89 per cent. 


\subsection{Demographic profile of the respondents}

The sample profile indicated that approximately, 63.1 per cent of the respondents were males $(n=170)$ while $36.9 \%$ per cent were females $(n=99)$. A majority of the respondents were in the 31-40 years age cohort (33.4 per cent; $n=90)$ while nearly half of the sample group were in possession of a Diploma as the highest qualification (42.2 per cent; $n=113$ ). Approximately, 64.1 per cent of the participants were married $(n=172)$ while 35.9 per cent $(n=97)$ purported to be single. The most frequently used mobile payment service was reported as the mobile prepaid payment service (38.4 per cent; $\mathrm{n}=103$ ) which encapsulates payments made for airtime, electricity, lotto etc. Relatedly, a majority of users indicated that they use M-payment services on a weekly basis (45.1 per cent; $n=121$ ).

\subsection{Reliability and validity of the study}

Following the two-step approach recommended by Anderson and Gerbing (1988), an initial examination of the measurement model to test reliability and validity was conducted. Secondly, the structural model was examined to test research hypotheses and model fitness. Structural equation modelling software LISREL was adopted to conduct a Confirmatory Factor Analysis (CFA) procedure and ascertain the validity of the study. Both convergent and discriminant validity were assessed. Convergent validity measures whether items can effectively reflect their corresponding factors whereas discriminant validity measures whether two factors are statistically different. Table 1 lists the descriptive statistics for each factor, standardized item loadings on each factor; the average variance extracted, composite reliability (CR) values, cronbach alpha values and the corresponding item-to-total correlations.

Table 1: Descriptive statistics and results of the CFA analysis of the instruments

\begin{tabular}{|c|c|c|c|c|c|c|c|c|}
\hline \multirow{2}{*}{ Factor } & \multirow{2}{*}{ Item } & \multicolumn{2}{|c|}{ Descriptive statistics } & \multicolumn{2}{|r|}{ Cronbach alpha test } & \multicolumn{3}{|r|}{ CFA test results } \\
\hline & & Mean & SD & \begin{tabular}{l|l}
$a$ \\
\end{tabular} & Item-to-total correlations & \begin{tabular}{l|l}
$\mathbf{C R}$ & \\
\end{tabular} & AVE & Standardised item loadings \\
\hline \multirow{4}{*}{ Service quality } & SQ1 & \multirow{4}{*}{4.09} & \multirow{4}{*}{.72} & \multirow{4}{*}{81} & .63 & \multirow{4}{*}{.81} & \multirow{4}{*}{.52} & .753 \\
\hline & SQ2 & & & & .69 & & & .765 \\
\hline & \begin{tabular}{|l|} 
SQ3 \\
\end{tabular} & & & & .72 & & & .776 \\
\hline & SQ4 & & & & .69 & & & .713 \\
\hline \multirow{3}{*}{ Satisfaction } & SAT1 & \multirow{3}{*}{4.07} & \multirow{3}{*}{.67} & \multirow{3}{*}{.83} & .69 & \multirow{3}{*}{.82} & \multirow{3}{*}{.52} & .856 \\
\hline & SAT2 & & & & .62 & & & .757 \\
\hline & SAT3 & & & & .69 & & & .750 \\
\hline \multirow{3}{*}{ Trust } & TRU1 & \multirow{3}{*}{4.15} & \multirow{3}{*}{.81} & \multirow{3}{*}{.79} & .73 & \multirow{3}{*}{.80} & \multirow{3}{*}{.53} & .757 \\
\hline & TRU2 & & & & .66 & & & .772 \\
\hline & TRU3 & & & & .64 & & & .721 \\
\hline \multirow{3}{*}{ Continuance intentions } & $\mathrm{Cl} 1$ & \multirow{3}{*}{4.02} & \multirow{3}{*}{.77} & \multirow{3}{*}{.79} & .51 & \multirow{3}{*}{.79} & \multirow{3}{*}{.56} & .808 \\
\hline & $\mathrm{Cl} 2$ & & & & .63 & & & .717 \\
\hline & $\mathrm{Cl} 3$ & & & & .70 & & & .716 \\
\hline
\end{tabular}

* Scores: 1 - Strongly Disagree; 3 - Neutral: 5 - Strongly Agree.

C.R.: Composite Reliability; AVE: Average Variance Extracted.

According to Chin (1998), research variables should have a composite reliability (CR) of more than 0.70 to infer high convergence among the constructs that have been identified in the conceptual framework (convergent validity). Composite reliability is a LISREL-generated estimate of internal consistency analogous to coefficient alpha (Forell \& Larcker 1981). Results presented in Table 1 indicate that, CR values for the four constructs ranged between 0.79 and 0.82 suggesting that each reflective construct in the proposed research model demonstrated high levels of reliability that more than met the standard thresholds. Table 2 also shows the Average Variance Extracted (AVE) estimates. AVE assesses the amount of variance captured by a construct's measure relative to measurement error and the correlations among the latent constructs in the model. An AVE estimate of 0.50 or higher indicates validity of a construct's measure. The AVE estimates in this study ranged between 0.52 and 0.56 thus achieving the required criterion for convergent validity. In addition, the item loadings ranged between 0.713 and $0.856(\geq 0.70)$, thus the scale has good convergent validity (Gefen et al., 2000). The results also indicate acceptable individual item convergent validity as more than fifty percent of each item's variance was shared with its respective construct (item-to-total correlations are all above 0.50). In addition, all Cronbach alpha values are larger than 0.70 , suggesting good reliability and internal consistency among the scale items (Zikmund \& Babin, 2007). 
Two tests were performed to check discriminant validity among factors. First, the researcher checked if the square of the parameter estimate between two constructs was less than the AVE estimates of the two constructs (Fomell and Larcker 1981). Second, as suggested by Hulland (1999) the researcher also checked if the correlations between the research constructs were less than 0.80 . Although the correlation values can be regarded to be generally moderate to high $(0.587 \leq r \leq 0.719)$, they are marginally acceptable.

Table 2: Inter-constructs correlation matrix

\begin{tabular}{|l|c|c|c|c|}
\hline \hline Research Constructs & SQ & TRU & SAT & Cl \\
\hline$\sqrt{\sqrt{A V} \mathrm{E}^{-}}$ & .721 & .728 & .721 & .748 \\
\hline Service quality (SQ) & 1 & & & \\
\hline Satisfaction (SAT) & .587 & .719 & 1 & \\
\hline Trust (TRU) & 0718 & 1 & & \\
\hline Continuance intentions (CI) & .633 & .616 & .708 & 1 \\
\hline (p<0.10; Sample size = 269)
\end{tabular}

As such, all criteria were adequately met across all possible pairs of constructs. For each factor, the square root of AVE is significantly larger than its correlation coefficients with other factors. This indicates good discriminant validity for the study (Fornell \& Larcker, 1981). In addition, the inter-factor correlation values fell below the limit of 0.80 and the highest correlation coefficient was lower than the square root of each factor AVE, indicating absence of multicolinearity problems and an indirect reflection of discriminant validity.

\subsection{Assessing Measurement Model Fit}

The second phase of the analysis comprised of making an estimate of the recommended and actual values of some fit indices for both CFA and the measurement model prior to examining structural model relationships. The goodness-of-fit index (GFI) and the adjusted goodness-of-fit index (AGFI) values were .90 and .88, respectively, which indicate marginal fit. However, Hoyle and Panter (1995) suggested that GFI and AGFI might suffer from inconsistencies as a result of unique sampling elements. Therefore, this study reports on four other fit indices that have been viewed as robust towards catering for sampling characteristics (Hair, Black, Babin, Anderson, Tatham, 2006), namely; the Comparative Fit Index (CFI=0.96), Incremental Fit Index (IFI=0.96), Normed Fit Index (NFI=0.91) and the Root Mean Square Error of Approximation (RMSEA=0.079). Values in the range equal or above 0.90 have been noted for $\mathrm{CFI}$, IFI and NFI indices, indicating adequate model fit. Moreover, a value less than the recommended threshold of 0.080 for RMSEA index was observed, demonstrating good model fit (Byrne, 2001; Hair et al., 2006).

\subsection{Structural model results}

Upon testing the structural model, factor loadings, path coefficients ( $\beta$ values), significance of each path estimate ( $p$ values) and the variance explained $\left(R^{2}\right)$ were examined. Path coefficients indicate the strength and direction of relationships between the independent variable and the dependent variable on the model whereas the $\mathrm{R}^{2}$ value signifies the amount of variance explained by independent variables. The statistical significance of each path coefficient was tested using a bootstrapping method with 300 re-samples to obtain the $t$-values for each path estimate (Chin, 1998). The $\mathrm{R}^{2}$ value for the one endogenous (dependent) variable, continuance intention $(\mathrm{Cl})$ was established at 0.639 . This result suggests that, on the overall; service quality, trust and satisfaction altogether explain about $64 \%$ of the variance in intention to make future M-payments, hence suggesting that these variables marginally explained the variations in $\mathrm{M}$ payment continuance intention among consumers, with the remaining $36 \%$ being accounted for by other variables which did not constitute part of this study.

The formula provided by Tenenhaus, Vinzi, Chatelin and Lauro (2005) for estimating the global goodness-of-fit $(\mathrm{GoF})$ statistic for the research model was calculated using the equation:

$\mathrm{GoF}=\sqrt{\sqrt{\mathrm{AVE}} * \overline{\mathrm{R}^{2}}}$

Where, AVE represents the average of all AVE values while $R^{2}$ represents the average of all $R^{2}$ values in the full path model. The calculated global goodness of fit (GoF) is 0.583 , which exceeds the threshold of GoF $>0.36$ suggested by Wetzels, Odekerken-Schröder and Van Oppen (2009). Thus, this study concludes that the research model has a good 
overall fit.

Table 3: Results of the Structural Equation Modelling

\begin{tabular}{|l|c|c|c|}
\hline Path & Hypothesis & Path coefficient (B) & Support/Reject hypothesis \\
\hline Service quality (SQ) $\rightarrow$ Satisfaction (SAT) & $\mathrm{H}_{1}$ & $.103^{n / s}$ & Reject \\
\hline Service quality (SQ) $\rightarrow$ M-payment Trust (TRU) & $\mathrm{H}_{2}$ & $.494^{\text {*t+* }}$ & Support \\
\hline M-payment Trust (TRU) $\rightarrow$ Satisfaction (SAT) & $\mathrm{H}_{3}$ & $.347^{\text {*t+ }}$ & Support \\
\hline Satisfaction (SAT) $\rightarrow$ Continuance Intention (CI) & $\mathrm{H}_{4}$ & $.514^{\text {*t+ }}$ & Support \\
\hline Trust (TRU) $\rightarrow$ Continuance Intention (CI) & $\mathrm{H}_{5}$ & $.223^{*}$ & Support \\
\hline
\end{tabular}

Table 3 present the results of the analysis on the structural model along with the path estimates. Support for the study hypotheses could be ascertained by examining the directionality (positive or negative) of the path coefficients and the significance of the $t$-values. The standardised path coefficients are expected to be at least 0.2 and preferably greater than 0.3 (Chin, 1998). Support is provided for three hypotheses $\left(\mathrm{H}_{2}, \mathrm{H}_{3}, \mathrm{H}_{4}\right.$ and $\left.\mathrm{H}_{5}\right)$ with path coefficients $(0.494,0.347,0.514$ and 0.223 , respectively) above 0.2 and significant $(p<0.001)$. However, the results posit that $\mathrm{H}_{1}$ although positive as hypothesised, depicts relationships that are insignificant $(\beta=0.103)$ and also fall outside the requisite rule of thumb of above 0.2 for path coefficients.

\section{Discussion of the Results}

The results indicate that service quality has a stronger effect on trust than it has on user satisfaction. Specifically, the first postulated hypothesis $\left(\mathrm{H}_{1}\right)$ was the relationship between service quality and user satisfaction $(\beta=.103 ; t=8.74)$. Although service quality has positive and significant effects on trust, the findings revealed that service quality has no significant effect on user satisfaction, contrary to the evidence from previous studies (Meharia, 2012; Deng et al., 2010; Chiou \& Droge, 2006). As such, these results conclude that the effects of service quality in the formation of satisfaction among users of M-payment services cannot be corroborated.

The second hypothesis, standalone path $\mathrm{H}_{2}$ between the independent variable (service quality) and the potential mediator (trust) had a $\beta$ of 0.494 and was significant at the $p<0.01$ level ( $t=11.276)$. This result supports the notion that providing quality services to users involves the expending of continuous effort and resource investment by service providers (Cenfetelli, Benbasat \& Al-Natour, 2008). Thus, service quality may act as a strong trust signal for users. If service providers cannot ensure service reliability, promptness and personalisation, users may doubt the service providers' ability and integrity to present quality mobile payment services to them, which will invariably decrease their trust of M-payment services (Zhou, 2013). Service providers can adopt encryption and certificates to ensure mobile payment security and reliability, otherwise, users may perceive great risk and lessen their usage of mobile payment. In addition, service providers are encouraged to present personalised services to users. For example, the use of locationbased services to acquire user location using mobile device GPS locators is suggested. This will enable the service providers to push context-related information such as nearby banks and automated teller machines to users. Such personalisation of services may help increase user trust (Lee, 2005).

Hypothesis 3 posited a positive association between M-payment trust with user satisfaction. A positive association between the two constructs was established $(\beta=0.347)$ and the relationship is significant at the $p<0.05$ level $(t=3.774)$, consistent with the predictions of the study and therefore $\mathrm{H}_{3}$ is supported. From the findings, it emerged that trust is a fundamental topic for M-payment research because it plays a role in creating satisfied users and an expected outcome as a result of the transaction process (Gefen \& Straub, 2003; Pavlou, 2003). Similarly, previous research proposes that perceived security and trust in vendors and payment systems is a significant determinant of mobile commerce success (Siau, Sheng \& Nah, 2004; Xu and Gutie' rrez, 2006). As such, trust has a positive impact on customer satisfaction and loyalty towards mobile payment services (Zhou, 2013; Lee \& Chung, 2009).

Regarding $\mathrm{H}_{4}$, the standardized coefficient and $t$-values between user satisfaction with continuance intentions ( $\beta=$ $0.514 ; t=11.702$ ) is positive and significant. Notably, the results of this study indicated that this standalone path had the highest predictive relationship in the entire model, significant at the $p<.01$ level. This is consistent with the prediction of $\mathrm{H}_{4}$ and is supported. Thus, a higher level of user satisfaction is associated with higher levels of M-payment technology usage. User satisfaction is considered to be a transient factor which should be scrutinised due to its importance in determining the success and the continued existence of specified services. Lin and Wang (2006) identified satisfaction as a strong predictor for users' intention to re-use of M-commerce while the article of Sanayei et al. (2011) addressed the 
notion that users' satisfaction had a significant influence on users' loyalty towards using M-payment. Furthermore, user satisfaction has been validated as a significant predictor of future intention to use a service i.e. re-purchase intention (Bhattacherjee, 2001; Oliver, 1980). As such, satisfied customers tend to purchase the same service again and use it more frequently than dissatisfied customers do. When customers evaluate M-payment service providers, they focus on the satisfaction they will derive from the service. Satisfaction will make the customers buy again and increase the frequency with which they utilise the mobile devices to make subsequent payments, thus developing a culture of Mpayments which is usually accompanied by increased tolerance to price changes (Grubb, 2012).

The results presented in table 3 support the reasoning that the higher the level of M-payment trust, the higher will be the desire to continue utilising the services for monetary payments $(\beta=0.223 ; t=5.713$ ). The positive association between trust and continuance intentions was significant at the $p<.10$ levels therefore, $\mathrm{H}_{5}$ is supported in this study. These findings lead to the conclusion that individuals use M-payment because they trust the system and this is consistent with a study by Zhou (2013) that pointed out a significant effect of trust on users' intention to use M-payment services. These results have also been corroborated in previous mobile banking studies of Kim et al. (2010); Koo and Wati (2010) as well as Lin (2011). Mobile payment is built on wireless networks and this involves great uncertainty and risk. Consequently, users need to build trust to ensure secure payment and good usage experiences into the future.

\section{Conclusions, Limitations and Future Research Directions}

Self-ratings of the study variables were collected from a limited sample size of 269 users located within the Gauteng province of South Africa. This implies that caution must be exercised when generalising the results to other geographical locations and upon deriving subsequent conclusions from this study. Moreover, the efficacy of M-payment continuance was solely assessed from the perspective of urban users, while considerable adoption has also been reported among rural dwellers in South Africa. The results would be more informative if data from both sides of the dyad were compared. For example, future studies may be conducted by using paired data from both rural and urban users of M-payment services situated across different provinces of the country. In addition, subsequent research should contemplate replicating this study in other developing countries for results comparisons. More studies of this nature are encouraged among dissimilar cultures while utilising better sampling methods, in order to establish the robustness of the scale as well as its cultural invariance. Future studies can also extend the current study conceptual framework by studying the effects of a larger set of variables. Of particular importance could be the consideration of the perceived value construct, as is has been suggested as the $21^{\text {st }}$ century replacement of service quality by some scholars (Sweeney \& Soutar, 2001).

\section{References}

Anderson, J. C. \& Gerbing, D. W. (1988). Structural equation modelling in practice: A review and recommended two-step approach. Psychological Bulletin, 103, 411-423.

Au, Y. A. \& Kauffman, R. J. (2008). The economics of mobile payments: Understanding stakeholder issues for an emerging financial technology application. Electronic Commerce Research and Applications, 7(2), 151-220.

Babin, L. A. \& Burns, A. C. (1998). A modified scale for the measurement of communication evoked mental imagery. Psychology and Marketing, 15, 261-278.

Bhattacherjee, A. (2001). An empirical analysis of the antecedents of electronic commerce service continuance. Decision Support Systems, 32 (2), 201-214.

Brady, M. K. \& Cronin, J. J. (2001). Some new thoughts on conceptualizing perceived service quality: A hierarchical approach. Journal of Marketing, 65(3), 34-49.

Byrne, B. M. (2001). Structural equation modeling with AMOS: Basic concepts, applications, and programming. Mahwah, NJ: Lawrence Erlbaum Associates, Publishers.

Cawley, A. \& Hynes, D. (2010). Evolving mobile communication practices of Irish teenagers. Aslib Proceedings: New Information Perspectives, 62(1), 29-45.

Cenfetelli, R. T., Benbasat, I. \&Al-Natour, S. (2008). Addressing the 'what and how' of online services: positioning supporting-services functionality and service quality for business-to consumer success. Information Systems Research, 19(2), 161-181.

Chandra, S., Srivastava, S. C. \& Theng, Y. L. (2010). Evaluating the role of trust in consumer adoption of mobile payment systems: An empirical analysis. Communications of the Association for Information Systems, 27, 561-588.

Chen, Y. \& Barnes, S. (2007). Initial trust and online buyer behavior. Industrial Management \& Data Systems, 107(1), 21-36.

Chin, W.W. (1998). Issues and opinion on structural equation modelling. MIS Quarterly, 22(1), 7-16.

Chiou, J. S. \& Droge, C. (2006). Service quality, trust, specific asset investment and expertise: Direct and indirect effects in a satisfaction-loyalty framework. Journal of the Academy of Marketing Science, 34(4), 613-627.

Churchill, G. A. (Jr) \& lacobucci, D. (2002). Marketing research: methodological foundations. (8th ed.). Fortworth: Harcourt College Publishers. 
Cronin, J. J. \& Taylor, S. A. (1992). Measuring service quality: a re-examination and extension. Journal of Marketing, $56(3), 5568$.

Cronin, J. J. \& Taylor, S. A. (1994), SERVPERF versus SERVQUAL: Reconciling performance based and perceptions-minusexpectations measurement of service quality, Journal of Marketing, 58(1), 125131.

Cronin, J. J., Brady, M. K. \& Hult, G. T. M. (2000). Assessing the effects of quality, value and customer satisfaction on consumer behavioral intentions in service environments, Journal of Retailing, 76(2), 193-218.

Dahlberg, T., Mallat, N., Ondrus, J. \& Zmijewska, A. (2008). Past, present and future of mobile payments research: a literature review, Electronic Commerce Research and Applications,7 (2), 165-181.

DeLone, W. H. \& McLean, E. R. (1992). Information systems success: the quest for the dependent variable. Information Systems Research, 3(1), 60-95.

DeLone, W. H. \& McLean, E. R. (2004). Measuring e-Commerce success: applying the DeLone \& McLean information systems success model. International Journal of Electronic Commerce, 9(1), 31-47.

Deng, Z. H., Lu, Y. B., Wei, K. K. \& Zhang, J. L. (2010). Understanding customer satisfaction and loyalty: an empirical study of mobile instant messages in China, International. Journal of Information Management, 30 (4), 289-300.

Fishbein, M. \& Azjen, I. (1975). Belief, attitude, intention and behaviour: An introduction to theory and research. Reading, MA: AddisonWesley.

Fornell, C. \& Larcker, D. F. (1981). Evaluating structural equation models with unobservable variables and measurement error. Journal of Marketing Research, 18(1), 39-51.

Gefen, D., Straub, D. W. \& Boudreau, M. C. (2000). Structural equation modelling and regression: guidelines for research practice. Communications of the Association for Information Systems, 4(7), 1-70.

Gefen, D. (2002). Reflections on the dimensions of trust and trustworthiness among online consumers. ACM SIGMIS Database. 33(30), 38-53.

Gefen, D. \& Straub, D. (2003). Managing user trust in B2C e-services. E-Service Journal, 2(2), 7-24.

Grubb, L. (2012). How ready is Africa for mobile payments? [Online] Available at: http://www.technologybanker.com/news-analysis/howready-is-africa-for-mobile-payments\#.U8kyuvmSw1Y. (Accessed on 18 July 2014).

Hair, Jr., J. F., Black, W. C., Babin, B. J, Anderson, R. E. \& Tatham, R. L. (2006). Multivariate Data Analysis, 6th ed. Upper Saddle River, NJ: Prentice Hall.

Hallowell, R. (1996). The relationships of customer satisfaction, customer loyalty and profitability: an empirical study. International Journal of Service Industry Management, 7(4), 27-42.

Hoyle, R. H. \& Panter, A. T. (1995). Writing About Structural Equation Models. In Structural Equation Modeling Concepts, Issues, and Applications (pp.158-176). Hoyle, R.H. (ed.). Newbury Park, CA: Sage Publications.

Hulland, J. (1999). Use of Partial Least Squares (PLS) in Strategic Management Research: A Review of Four Recent Studies. Strategic Management Journal, 20(2), 195-204.

International telecommunications union (2001). International Telecommunications Union (ITU) (2001). Yearbook of statistics: Telecommunication services, 1990-1999. Geneva. Available at http://www.itu.int.pdf. (Accessed on 30/09/2013).

Jarvenpaa, S. L., Lang, K. R., Takeda, Y. \& Tuunainen, V. K. (2003). Mobile commerce at crossroads. Communications of the ACM, 46(12), 41-44.

Kim, B., Choi, M. \& Han, I. (2009). User behavior toward mobile data services: the role of perceived fee and prior experience. Expert Systems with Applications, 36(4), 8528-8536.

Kim, C., Mirusmonov, M. \& Lee, I. (2010). An empirical examination of factors influencing the intention to use mobile payment. Computers in Human Behavior, 26(3), 310-322.

Koo, C. \& Wati, Y. (2010). Toward an understanding of the mediating role of trust in mobile banking service: an empirical test of Indonesia Case. Journal of Universal Computer Science, 16(3), 1801-1824.

Kuo, Y-F., Wu, C-M. \& Deng, W-J. (2009). The relationships among service quality, perceived value, customer satisfaction and postpurchase intention in mobile value-added services. Computers in Human Behavior, 25(4), 887-896.

Lee, T. (2005). The impact of perceptions of interactivity on customer trust and transaction intentions in mobile commerce. Journal of Electronic Commerce Research, 6(3), 165-180.

Lee, K. C. \& Chung, N. (2009). Understanding factors affecting trust in and satisfaction with mobile banking in Korea: A modified DeLone and McLean's model perspective. Interacting with Computers, 21(5), 285-392.

Lin, C. S., Wu, S. \& Tsai, R. J. (2005). Integrating perceived playfulness into expectation confirmation model for web portal context. Information \& Management Journal, 42(5), 683-693.

Lin, H. H. \& Wang, Y. S. (2006). An examination of the determinants of customer loyalty in mobile commerce contexts, Information and Management, 43(8), 271-282.

Lin, H-F. (2011). An empirical investigation of mobile banking adoption: The effect of innovation attributes and knowledge-based trust. International Journal of Information Management, 31, 252-260.

Lu, Y., Cao, Y., Wang, B. \& Yang, S. (2011). A study on factors that affect users' behavioral intention to transfer usage from the off-line to the online channel. Computers in Human Behavior, 27, 355-364.

Lu, Y., Zhang, L. \& Wang, B. (2010). A multidimensional and hierarchical model of mobile service quality. Electronic Commerce Research and Applications, 8(5), 228-240.

Luo, X., Li, H., Zhang, J. \& Shim, J. P. (2010). Examining multi-dimensional trust and multi-faceted risk in initial acceptance of emerging technologies: an empirical study of mobile banking services, Decision Support Systems, 49(2), 222-234. 
Mastercard Report (2012). The mobile payments readiness index: a global market assessment. [Online] Available at: http://mobilereadiness.mastercard.com/globalreport.pdf. (Accessed 18 July 2014).

Mayer, R. C, Davis, J. H. \& Schoorman, F.D. (1995). An integrative model of organizational trust. Academy of Management Review, 20(3), 709-734.

McKnight, D. H., Choudhury, V. \& Kacmar, C. (2002). Developing and validating trust measures for e-commerce: An integrative typology. Information Systems Research, 13(3), 334-359.

Meharia, P. (2012). Assurance on the reliability of mobile payment system and its effects on use: An empirical examination. Journal of Accounting \&Management Information Systems, 11(1), 97-111.

Misra, S. \& Wickamasinghe, N. (2004). Security of a mobile transaction: A trust model. Electronic Commerce Research, 4(4), $359-372$.

Oliver, R. L. (1980). A Cognitive Model of the Antecedents and Consequences of Satisfaction Decisions, Journal of Marketing Research, 17 (November), 460-469.

Oliver, R. L. (1993). Cognitive, affective and attribute bases of the satisfaction response. Journal of Consumer Research, 20(3), 418-430.

Olsen, L. L. \& Johnson, M. D. (2003). Service equity, satisfaction and loyalty: from transaction-specific to cumulative evaluations, Journal of Service Research, 5 (3), 184-195.

Pavlou, P. A. (2003). Consumer acceptance of electronic commerce: Integrating trust and risk with the technology acceptance model. International Journal Electronic Commerce, 7(3), 69-103.

Parasuraman, A., Zeithaml, V. A. \& Berry, L. L. (1988). SERVQUAL: a multiple-item scale for measuring consumer perceptions of service quality. Journal of Retailing, 64(1), 12-41.

Parasuraman, A., Zeithaml, V. A. \&Malhotra A. (2005). E-S-QUAL: A multiple-item scale for assessing electronic service quality. Journal of Service Research, 7(3), 213-233.

Porteus, M. (2006). The enabling environment for mobile banking in Africa. Department for International Development Report. Bankable Frontiers Associates: USA.

Pousttchi, K., Schiessler, M. \& Wiedemann, D. G. (2008). Proposing a comprehensive framework for analysis and engineering of mobile payment business models. Information Systems and e-Business Management, 7(3), 363-393.

Rust, R. T. \& Oliver, R. L. (1994). Service Quality: Insights and Managerial Implications from the Frontier. In Service Quality: New Directions in Theory and Practice. (Pp. 1-19). London: Sage Publications.

Sanayei, A., Ranjbarian, B., Shaemi, A. \&Ansari, A. (2011). Determinants of customer loyalty using mobile payment services in Iran. Interdisciplinary Journal of Contemporary Research in Business, 3(6, 22-34.

Siau, K., \& Shen, Z. (2003). Building customer trust in mobile commerce. Communications of the ACM, 46(4), 91-94.

Siau, K., Sheng, H. \& Nah, F. (2004). Development of a framework for trust in mobile commerce. In Proceedings of 2nd annual workshop on $\mathrm{HCl}$ research in MIS. Seattle.

Shin, D. \& Kim, W. (2008). Forecasting customer switching intention in mobile service. Technological Forecasting and Social Change, 75(6), 854-874

Smith, A.K., Bolton, R. N. \& Wagner, J. (1999). A model of customer satisfaction with service encounters involving failure and recovery. Journal of Marketing Research 36(3), 356-372.

Sweeney, J. C. \& Soutar, G. N. (2001). Consumer perceived value: the development of a multiple item scale. Journal of Retailing, $77(2)$, 203-220.

Tenenhaus, M., Vinzi, V. E., Chatelin, Y. -M. \& Lauro, C. (2005). PLS Path Modeling. Computational Statistics and Data Analysis, 48(1), 159-205.

Van der Heijden, H., Verhagen, M. \& Creemers, M. (2003). Understanding online purchase intentions: contributions from technology and trust perspectives. European Journal of Information, 12, 41-48.

Wang, Y. S. \& Liao, Y. W. (2007). The conceptualization and measurement of m-commerce user satisfaction. Computers in Human Behavior, 23(1), 381-398.

Wetzels, M., Odekerken-Schröder, G. \& Van Oppen, C. (2009). Using PLS path modeling for assessing hierarchical construct models: guidelines and empirical illustration. Management Information Systems Quarterly, 33(1), 177-195.

Xu, G. \& Gutie'rrez, J. A. (2006). An exploratory study of killer applications and critical success factors in M-commerce. Journal of Electronic Commerce in Organizations, 4 (3), 63-79.

Yeh, Y. S. \& Li, Y. M. (2009). Building trust in m-commerce: Contributions from quality and satisfaction. Online Information Review, Vol. 33(6), 1066-1086.

Zeithaml, V. A., Berry, L. L. \& Parasuraman, A. (1996). The behavioral consequences of service quality. The Journal of Marketing, 60, 31-46.

Zikmund, W. G. \& Babin, B. J. (2007). Exploring marketing research. (9th ed.). USA: Thomson South-Western Publishers.

Zhao, L., Lu, Y, Zhang, L. \& Chau, P. Y. K (2012). Assessing the effects of service quality and justice on customer satisfaction and the continuance intention of mobile value-added services: An empirical test of a multidimensional model. Decision Support Systems, 52(3), 654-656.

Zhou, T. (2013). An empirical examination of continuance intention of mobile payment services. Decision Support Systems, 54, 10851091.

Zmijewska, A., Lawrence, E. \& Steele, R. (2004). Classifying M-payments. Paper Presented at the third International Conference on Mobile Business, New York,USA. 